\title{
Correspondence
}

To the Editors

\section{Current Practice: Febrile seizures}

Sri Lanka Journal of Child Health, 2010; 39: 121

(Key words: Febrile seizures)

I wish to draw your attention to the following statement found in the article febrile seizures in Sri Lanka Journal of Child Health, 2009; 38: 93-97

'........Those lasting longer or occurring after the first $\mathbf{2 4}$ hours or having multiple seizures during the same febrile illness or convulsions affecting one side of the body or occurrence of focal neurological deficits are called complex febrile seizures $(9-35 \%) \ldots$..'

I think the impression given that the seizures occurring within 1 st 24 hours of a febrile illness is simple and those after the 1 st 24 hours are complex is incorrect according to the standard definitions or international classifications. I would be grateful if you could clarify the matter.

A LakKumar Fernando

Consultant Paediatrician,

General Hospital, Gampaha, Sri Lanka

$\underline{\text { Response by author of article }}$

With regard to the article on febrile seizures published in the September 2009 issue, several colleagues have raised queries regarding the description on types of febrile seizure outlined in this article.

I would be grateful if you could kindly change the wording in this description to read as 'simple febrile seizures are seizures that are brief (less than 15 minutes), generalised and do not recur within 24 hours. Complex febrile seizures are those which are prolonged (15 minutes or more) or have focal features or recur within 24 hours'.

I sincerely regret the inconvenience and apologise to the readership for the confusion that may have resulted from the ambiguity in the wording in the previous text.

J Wanigasinghe

Senior Lecturer in Paediatrics \& Honorary Consultant Paediatric Neurologist,

Faculty of Medicine, University of Colombo

Editorial Comment

According to the currently accepted definitions, seizures recurring after 24 hours will be 'simple febrile seizures' rather than 'complex febrile seizures'. This is an ambiguous and untenable position. I think the definitions should be altered as follows: 'Simple febrile seizures' are seizures that are brief (less than 15 minutes), generalised and do not recur within the same febrile illness and 'complex febrile seizures' are seizures that are prolonged (15 minutes or more), focal or recur within the same febrile illness.

G N Lucas

Joint Editor 